\title{
Model Servqual Rule Base Asean University Network untuk Penilaian Kualitas Program Studi
}

\author{
Esti Wijayanti ${ }^{a^{*}}$, Farikhin $^{\mathrm{b}}$, Rahmat Gernowo ${ }^{\mathrm{c}}$

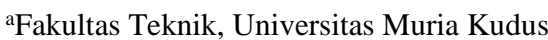 \\ bJurusan Matematika, Fakultas Sains dan Matematika, Universitas Diponegoro \\ 'Jurusan Fisika, Fakultas Sains dan Matematika, Universitas Diponegoro
}

Naskah Diterima : 12 Maret 2016; Diterima Publikasi : 25 Mei 2016

DOI: $10.21456 /$ vol6iss1pp59-65

\begin{abstract}
As well known that AUN (Asean University Network.AUN) and ABET (Accreditation Boardb for Enginnering and Technology) are non-profit organitatinon which have. AUN (Asean University Network) were using variable with refer to AUN's criteria's there consist of fifteen which are: expected learning outcomes, programme specification, programme structure and content, teaching and learning strategy, student assessment, academic staff quality, support staff quality, student quality, student advice and support, facilities and infrastructure, quality assurance of teaching/learning process, staff development activities, stakeholders feedback, output, stakeholders satisfaction, and adopted score's scale 7. In there here, we discuss the fifteen AUN's of AUN in the criterias. There servqual of as can be into five dimensions which are: assurance, empathy, responsive, reliability and facilty in order to make the assessment's process easier. This research outcome indicated that this proposed method can be used to evaluate an education program. The validation result by using AUN's data and the analysis of servqual rule base Asean University Network almost have the same pattern with correlation value is 0,985 and this is can be accepted because its validity have reach $97 \%$.
\end{abstract}

Keywords : Servqual; Rule Base Asean University Network; Asean University Network

\begin{abstract}
Abstrak
Evaluasi program studi ditingkat internasional sebagai contoh adalah ABET dan Asean Univervisty Network. AUN adalah kepanjangan dari Asean University Network, variabel yang digunakan ada 15 kriteria yaitu: Expected Learning Outcomes, Programme Specification, Programme Structure and Content, Teaching and Learning Strategy, Student Assessment, Academic Staff Quality, Support Staff Quality, Student Quality, Student Advice and Support, Facilities and Infrastructure, Quality Assurance of Teaching/Learning Process, Staff Development Activities, Stakeholders Feedback, Output, Stakeholders Satisfaction yang mengadopsi skala skor 7. Dengan menggunakan penilaian dari Asean University Network sebagai analisis data yang dikumpulkan, metode servqual untuk evaluasi cocok untuk penilaian servqual rule base AUN. Karena AUN ada 15 kriteria dan akan ditransformasikan kedalam penilaian servqual yang hanya menjadi 5 dimensi yaitu dimensi assurance, empathy, responsive, reliability dan fasilitas sehingga mempermudah assessment. Hasil penelitian menunjukkan bahwa metode yang diusulkan dapat digunakan untuk mengevaluasi sebuah program studi. Validasi mengunakan data AUN dan dibandingkan dengan analisis servqual rule base Asean University Network diperoleh nilai kolerasi yang hampir satu pola yaitu 0,985 dan perhitungan diterima karena tingkat validitas mencapai $97 \%$.
\end{abstract}

Kata kunci: Servqual; Rule base Asean University Network; Program Studi.

\section{Pendahuluan}

Model terbaru servqual dikombinasikan dengan teori fuzzy dan metode analytic hirarki proses yang secara efektif menangani ketidakpastian dalam kinerja pelayanan. Teori Fuzzy dianggap dapat menangani ketidak pastian tersebut, sedangkan metode AHP diadopsi sebagai alat untuk memperkirakan bobot pentingnya atribut layanan strategis. Analisis strategis hirarki nilai layanan pada program Teknik Manajemen di Universitas Palermo

*) Penulis korespondensi: esti.wijayanti@msi.undip.ac.id
(Italia) mengunakan analisis layanan yang memungkinkan faktor kinerja pelayanan yang paling berpengaruh. Hasil yang diperoleh menunjukkan bahwa persepsi para profesor kualitas pelayanan mempengaruhi layanan performa tingkat secara keseluruhan penilaian (Lupo, 2013).

Untuk mengetahui kualitas layanan yang menjadi prioritas untuk ditingkatkan kualitas layanannya dan mengetahui tingkat segmentasi pelanggan dengan menggunakan metode servqual yang meliputi 5 dimensi utama yaitu Tangibles, Reliability, 
Responsiveness, Assurance dan Emphaty dan Analytic Hierarchy Process (Purnamawati, 2009).

Penilaian kualitas layanan sekolah pascasarjana di universitas non Islam Azad University Khorasgan mengukur kualitas mengunakan standar servqual yang menekankan pada tingkat kualitas saat ini dengan yang diharapkan. Hasil penelitian menunjukkan perbedaan yang signifikan antara harapan mahasiswa dan tingkat kualitas pelayanan saat ini. Variabel lain yang meningkat dalam urutan ini adalah empathy, assurance, tangibles dan kepercayaan dalam pelayanan kualitas (Ali et al., 2011).

Kualitas pelayanan pendidikan tinggi di Thailand yang diteliti secara khusus, dengan meneliti lima dimensi servqual instrumentasi (keandalan, jaminan, bukti fisik, empati, dan responsif). Penelitian tersebut meneliti validitas dan kehandalan servqual dalam menilai pendidikan tinggi di Thailand. Di semua lima dimensi kualitas pelayanan, kesenjangan yang diteliti antara persepsi mahasiswa dan harapan sebagai berikut: Keandalan: -2,25, Responsiveness: -2,72, Assurance: -2,48, empathy: -2,48, Tangibles: -2,88. Analisis kesenjangan antara persepsi dan harapan layanan menunjukkan bahwa semua skor untuk persepsi lebih rendah dari skor harapan mereka, menunjukkan bahwa ada banyak perbaikan layanan upaya perlu dipenuhi untuk meningkatkan kualitas pelayanan. Akibatnya untuk institusi untuk meningkatkan pelayanan yang dibutuhkan untuk membenahi fasilitas dan peralatan dalam rangka mengurangi kesenjangan antara persepsi dan harapan (Yousapronpaiboon, 2014).

Badan Accreditation Board for Engineering and Technology (ABET) telah mengeluarkan sejumlah pedoman umum untuk menilai perbaikan secara terus-menerus (kriteria 4) tetapi tidak mendukung metode tertentu atau proses untuk melakukannya. Akibatnya, banyak universitas mencari akreditasi dari organisasi telah mengembangkan dengan metode mereka sendiri untuk memenuhi kriteria yang tertentu. Tujuan dari penelitian tersebut ada dua yaitu untuk menyajikan dan meninjau secara kritis sejumlah metode yang digunakan oleh rekayasa ABET-terakreditasi program untuk menilai peningkatan kualitas terus menerus, dan untuk menyajikan dan modifikasi sebuah metode baru dan lebih efisien berdasarkan analisis cohort (Aoudia et al., 2015).

Kriteria ABET untuk Akreditasi Program Teknik didasarkan pada pengetahuan, keterampilan dan tingkah laku mahasiswa melalui kurikulum. Mengakuisisi pengetahuan keterampilan dan perilaku yang dianggap sebagai student outcomes (SOs). Akibatnya program perlu mengatur SOS sendiri untuk mencapai tujuan program educational objectives (PEOs). Pencapaian tujuan dan sasaran program diverifikasi oleh penilaian dan evaluasi SOS dan PEO. Proses pengembangan program untuk akreditasi dan pembentukan proses dibahas secara rinci. Proses ini berlaku untuk memenuhi Kriteria ABET 2014 untuk akreditasi baru dan B.Sc. ada Program rekayasa. Proses ini dapat menghasilkan menyesuaikan PEO, SOS dan kurikulum (Khan et al., 2014).

Evaluasi suatu program studi sangat penting untuk meningkatkan kualitas suatu program studi baik di internal maupun ekternal. Evaluasi program studi internasional salah satunya yaitu AUN. AUN adalah kepanjangan dari Asean University Network di bidang sains, syarat untuk penilaian AUN yang pertama perguruan tinggi atau universitas telah menjadi anggota atau anggota terafiliasi AUN, yang kedua harus memiliki setidaknya tiga lulusan dari program yang sama pada saat permohonan untuk di visitasi dan universitas terdaftar atau lembaga pendidikan yang telah disetujui oleh pemerintah atau otoritas lokal sebagai pendidikan tinggi yang berakreditasi A.

Dalam kriteria AUN mengunakan 15 kriteria yaitu: Expected Learning Outcomes, Programme Specification, Programme Structure and Content, Teaching and Learning Strategy, Student Assessment, Academic Staff Quality, Support Staff Quality, Student Quality, Student Advice and Support, Facilities and Infrastructure, Quality Assurance of Teaching/Learning Process, Staff Development Activities, Stakeholders Feedback, Output, Stakeholders Satisfaction. AUN mengadopsi skala rating 7 poin untuk penilaian kualitas. Scaling bertujuan untuk menawarkan universitas dan penilaian eksternal instrumen untuk skala putusan mereka dan untuk melihat seberapa jauh mereka telah berkembang dalam perjalanan ke pertemuan kriteria dan melihat seberapa jauh kualitas terjamin. Arti dari nilai di skala skor 7 titik adalah sebagai berikut: 1 = tidak ada (tidak ada dokumen, tidak ada rencana, tidak ada bukti), $2=$ subjek ini dalam tahap perencanaan, $3=$ dokumen yang tersedia, tetapi tidak ada bukti yang jelas bahwa mereka digunakan, 4 = dokumen yang tersedia dan bukti bahwa mereka digunakan, 5 = bukti yang jelas pada efisiensi aspek, $6=$ contoh praktik terbaik, $7=$ sangat baik (dunia kelas atau praktek terkemuka). Untuk menilai kualitas pengajaran dan pembelajaran, angka memiliki kata-kata yang berbeda tetapi lebih atau kurang arti yang sama. Penilaian dari kualitas program juga dilakukan pada skala 7 titik. Untuk melihat kegiatan kualitas dan perbaikan, skala 7 titik bisa juga dibaca sebagai berikut $1=$ benar-benar tidak memadai; perbaikan segera harus dilakukan, 2 = tidak memadai, perbaikan yang diperlukan, 3 = tidak memadai, tetapi perbaikan kecil akan membuat memadai, 4 = memadai seperti yang diharapkan (memenuhi pedoman AUN-QA dan kriteria), $5=$ baik dari cukup (melebihi pedoman AUN-QA dan kriteria), $6=$ contoh praktik terbaik, $7=$ sangat baik 
(dunia kelas atau praktek terkemuka) (Gajaseni, 2011).

Asean University Network merupakan standarisasi asean untuk mengevaluasi dan melaporkan integrasi praktik yang ada di program studi. Ketercapaian peningkatan mutu akan dapat diketahui dengan jelas. Dengan demikian peran auditor sangat menentukan apakah program studi bersangkutan telah memenuhi semua kriteria penilaian dengan rule AUN, apabila program studi tersebut memenuhi nilai 4,00 point maka program studi itu dinyatakan member AUN. Tujuan penelitian ini adalah modifikasi model ServQual rule base Asean University Network untuk penilaian kualitas program studi dengan pedoman penilain Asean University Network.

\section{Kerangka Teori}

\subsection{Servqual}

Sebelum menghitung score servqual, maka terlebih dahulu menghitung rata - rata score dari tiap atribut dari ekspektasi dan persepsi yang diformulasikan sebagai berikut:

$$
\overline{\mathrm{x}} E_{\mathrm{i}}=\frac{\sum E_{i}}{\mathrm{n}}
$$

$$
\overline{\mathrm{x}} P_{\mathrm{i}}=\frac{\sum P_{\mathrm{i}}}{\mathrm{n}}
$$

Dimana:

$\overline{\mathrm{x}} P_{\mathrm{i}}=$ nilai rata-rata sampel persepsi (tanggapan) tiap atribut kualitas ke $\mathrm{i}$

$\overline{\mathrm{x}} E_{\mathrm{i}}=$ nilai rata-rata sampel ekspektasi (harapan) tiap atribut kualitas ke $\mathrm{i}$

$\sum P_{i}=$ total nilai persepsi tiap atribut kualitas seluruh kriteria

$\sum E_{i}=$ total nilai ekspektasi tiap atribut kualitas seluruh kriteria

$\mathrm{n}=$ Jumlah criteria

Nilai servqual merupakan selisih antara nilai persepsi dengan nilai ekspektasi, dan diformulasikan sebagai berikut

$$
\mathrm{SS}_{\mathrm{i}}=\overline{\mathrm{x}} \mathrm{P}_{\mathrm{i}}-\overline{\mathrm{xE}} \overline{\mathrm{i}}
$$

Dimana:

$S S_{\mathrm{i}}=$ servqual score tiap atribut kualitas.

\subsection{Servqual Rule base Asean University Network}

\begin{tabular}{|c|c|c|c|}
\hline No & Kriteria & $\begin{array}{l}\text { Dimensi } \\
\text { Servqual }\end{array}$ & $\begin{array}{l}\text { Skor } \\
\text { Nilai } \\
(1-7)\end{array}$ \\
\hline 1 & $\begin{array}{l}\text { Expected Learning } \\
\text { Outcomes }\end{array}$ & $\begin{array}{l}\text { Dimensi } \\
\text { Assurance }\end{array}$ & \\
\hline 2 & $\begin{array}{l}\text { Quality Assurance } \\
\text { of Teaching and } \\
\text { Learning Process }\end{array}$ & & \\
\hline 3 & $\begin{array}{l}\text { Stakeholders } \\
\text { Feedback }\end{array}$ & & \\
\hline 4 & Student Quality & Dimensi & \\
\hline 5 & $\begin{array}{l}\text { Student Advice and } \\
\text { Support }\end{array}$ & Empathy & \\
\hline 6 & Output & & \\
\hline 7 & $\begin{array}{l}\text { Programme } \\
\text { Specification }\end{array}$ & $\begin{array}{l}\text { Dimensi } \\
\text { Responsive }\end{array}$ & \\
\hline 8 & Student Assessment & & \\
\hline 9 & $\begin{array}{l}\text { Academic staff } \\
\text { quality }\end{array}$ & $\begin{array}{l}\text { Dimensi } \\
\text { Reliability }\end{array}$ & \\
\hline 10 & $\begin{array}{l}\text { Programme } \\
\text { Structure and } \\
\text { Content }\end{array}$ & & \\
\hline 11 & $\begin{array}{l}\text { Teaching and } \\
\text { Learning Strategy }\end{array}$ & & \\
\hline 12 & $\begin{array}{l}\text { Stakeholders } \\
\text { Satisfaction }\end{array}$ & & \\
\hline 13 & $\begin{array}{l}\text { Staff Development } \\
\text { Activities }\end{array}$ & $\begin{array}{l}\text { Dimensi } \\
\text { Fasilitas }\end{array}$ & \\
\hline 14 & $\begin{array}{l}\text { Support Staff } \\
\text { Quality }\end{array}$ & & \\
\hline 15 & $\begin{array}{l}\text { Facilities and } \\
\text { Infrastructure } \\
\text { Jumlah Skor }\end{array}$ & & \\
\hline
\end{tabular}

Adapun tabel untuk pengujian validitas yang ditunjukan pada Tabel 1.

\subsection{Uji Performa Statistik}

Pengukuran performa statistik berikutnya yaitu menggunakan korelasi, yaitu dengan melakukan perhitungan perbedaan antara data asli dengan data hasil model yang diteliti. Perbedaan tersebut diabsolutkan kemudian dihitung kedalam bentuk persentase terhadap data asli. Pengukuran performa statistik dengan regresi dapat dilihat pada persamaan (1), (Sudjana, 2005):

$$
r=\frac{n \sum x i, y i-\sum x i \sum y i}{\sqrt{\left(n \sum x i^{2}-\left(\sum x i\right)^{2}\right)\left(n \sum y i^{2}-\left(\sum y i\right)^{2}\right.}}
$$

(4)

Keterangan:

$\begin{array}{ll}\mathrm{r} & \text { : koefisien korelasi } \\ \mathrm{x} & \text { : variable } \mathrm{x} \\ \mathrm{y} & \text { : variable } \mathrm{x} \\ \mathrm{n} & \text { : jumlah data }\end{array}$




\section{Metodologi}

Proses servqual rule base Asean University Network merupakan atuaran penilaian Asean University Network yang memiliki lima belas kriteria dan akan memperoleh label Asean University Network kalau nilainya mencapai 4,00, dari lima belas kriteria tersebut akan ditansformasikan menjadi lima dimensi yang ada pada servqual yaitu dimensi assurance, dimensi empathy, dimensi responsive, dimensi reliability dan dimensi fasilitas. Validasi dari performa servqual rule base AUN menggunakan penghitungan nilai korelasi regresi. Gambar 2 menunjukkan diagram alir servqual rule base AUN.

Pada proses penilaian servqual rule base AUN diperoleh nilai masing-masing dimensi yang mana dimensi yang nilainya paling kecil akan di evaluasi dan sistem akan membreak down masing-masing kriteria AUN. Berikut ini adalah diagram alir proses servqual rule base AUN yang ditunjukan pada Gambar 1.

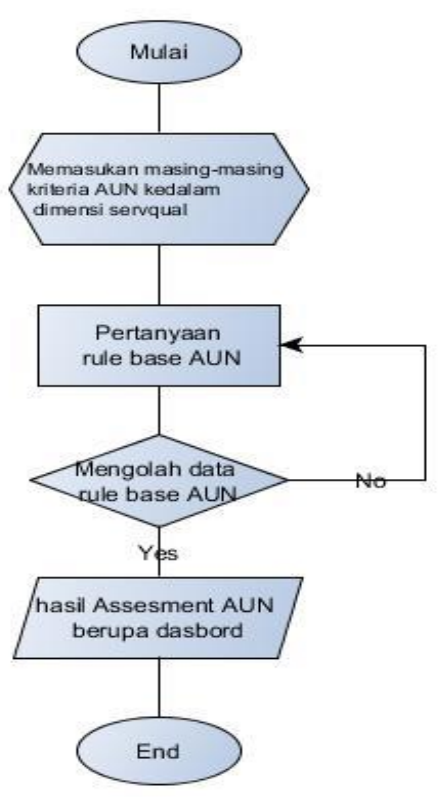

Gambar 1. Diagram Alir Proses servqual rule base AUN

Dalam pembuatan rule based dalam penelitian Asean University Network. Rule Based tersebut disusun sebagai berikut :

R1 : IF (nilai assessment=1) Then sebutannya adalah menyeluruh dan mendesak (verry inadequate)

R2 : IF (nilai assessment=2) Then sebutannya adalah Perbaikan mayor (absolutely inadequate)
R3 : IF (nilai assessment=3) Then sebutannya adalah Perbaikan minor (Inadequate)

R4 : IF (nilai assessment=4) Then sebutannya adalah cukup (Adequate as Expected)

R5 : IF (nilai assessment=5) Then sebutannya adalah baik dari cukup (Better than Adequate)

R6 : IF (nilai assessment=6) Then sebutannya adalah praktik terbaik (good)

R7 : IF (nilai assessment=7) Then sebutannya adalah sangat baik (excellent)

R8 : IF (nilai Assesment prodi > 4,00) Then prodi akan menerima label atau terakreditasi AUN

R9 : IF (nilai Assesment prodi < 4,00) Then prodi akan menerima evaluasi dari asesor bagian dimensi servqual yang mana yang perluh diperbaiki

\section{Hasil dan Pembahasan}

Hasil penelitian metode servqual rule base Asean University Network untuk penilaian kualitas program studi adalah penilaian Asean University Network dengan kerangka servqual yaitu dimensi assurance, empathy, responship, reliability, dan fasilitas sehingga dapat diketahui nilai program studi dimana dari dimensi tersebut yang nilainya minimum dijadikan bahan evaluasi. Sehingga dengan adanya penelitian ini ketua jurusan dapat mempediksi capaian Asean University network dapat menilai kelima dimensi dari servqual serta dapat mengetahui evaluasi kriteria yang mana yang nilainya harus diperbaiki. Sebelum dilakukan penelitian atau eksperimen, dilakukan testing terhadap beberapa parameter untuk menguji kehandalan dari metode servqual rule base AUN, yaitu dengan membandingkan jumlah variabel yaitu variable AUN yang berjumlah lima belas dan servqual rule base AUN yang berjumlah 5. Perbandingan penggunaan data pada proses pembelajaran yang ditunjukan pada Tabel 2.

Tabel 2. Perbandingan Nilai regresi berdasarkan penggunaan data AUN

\begin{tabular}{lllll}
\hline & $\begin{array}{l}\text { AUN } \\
(\mathrm{x})\end{array}$ & $\begin{array}{l}\text { Servqual } \\
(\mathrm{y})\end{array}$ & $\mathrm{x} . \mathrm{y}$ & $\mathrm{x}^{2}$ \\
\hline $\begin{array}{l}\text { Chemical } \\
\text { Engineering } \\
\text { Mechanical }\end{array}$ & 4.27 & 4.23 & 18.06 & 18.23 \\
$\begin{array}{l}\text { Engineering } \\
\text { Public }\end{array}$ & 4.07 & 4.07 & 16.56 & 16.56 \\
$\begin{array}{l}\text { Health } \\
\begin{array}{l}\text { Total } \\
\text { Total^2 }\end{array}\end{array}$ & 4.2 & 4.15 & 17.43 & 17.64 \\
\hline
\end{tabular}




$$
\begin{aligned}
& r_{x y}=\frac{3(52,057)-12,54 * 12,45}{\sqrt{0,0618 * 0,0384}} \\
& r_{x y}=\frac{0,048}{\sqrt{0,00237}} \\
& r_{x y}=\frac{0,048}{0,049396} \\
& r_{x y}=0,971
\end{aligned}
$$

Maka dari hasil penelitian ini diperoleh nilai ratarata korelasi 0,985 mengunakan (4) dan hasil uji coba mengunakan SPSS menunjukkan nilai koefisien determinasi 0,971 dengan hasil $\mathrm{KD}=\mathrm{R} * \mathrm{R} * 100 \%=$ $97 \%$ dan diperoleh $\mathrm{R}=0,971$, sedangkan nilai uji $\mathrm{F}=33.333$ dengan signifikan $0,109<0,05$ maka menunjukkan regresi dapat dipercaya sebagai interpestasi model.

Untuk penelitian servqual rule base Asean University Network megunakan data dari program studi yang sudah berlabel Asean University Network yaitu Teknik Mesin Universitas Diponegoro Semarang, berikut ini adalah pemaparan hasil uji Program Studi Teknik Mesin.

Penilaian atau hasil assessment Asean University Network Program Studi Teknik Mesin Universitas Diponegoro dengan skor 4,07 dan dengan hasil assessment servqual rule base Asean University Network yaitu dengan skor 4,07. Berikut ini adalah hasil kolerasi antara penilaian Asean University Network dengan servqual rule base Asean University Network. Hasil asssesment AUN dengan objek Teknik Mesin UNDIP yang ditunjukan pada Gambar 2.

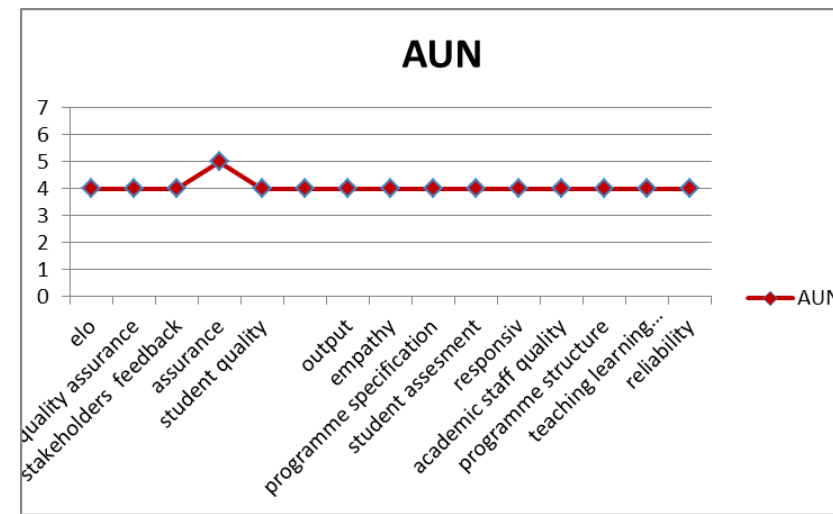

Gambar 2. Hasil asssesment AUN dengan objek Teknik Mesin UNDIP

Berikut ini adalah dengan hasil assessment servqual rule base Asean University Network yang akan disimulasikan dengan grafik. Hasil asssesment servqual rule base AUN dengan objek Teknik Mesin UNDIP yang ditunjukan pada Gambar 3.

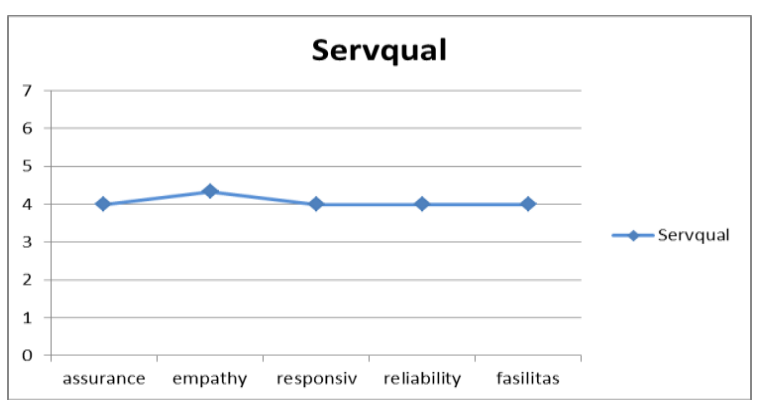

Gambar 3. Hasil asssesment servqual rule base AUN dengan objek Teknik Mesin UNDIP

Dengan hasil correlation yang hampir satu pola atau trend maka diterima. Simulasi grafik untuk penilaian AUN dan servqual rule base AUN ditunjukkan pada Gambar 4.

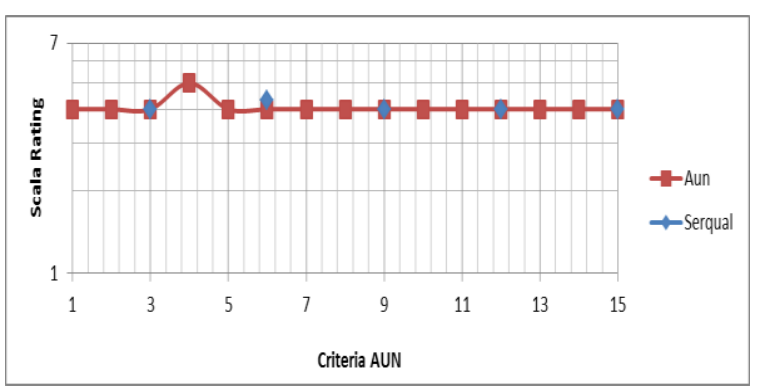

Gambar 4. Hasil kolerasi AUN dan asssesment servqual rule base AUN dengan objek Teknik Mesin UNDIP.

Selanjutnya adalah proses servqual rule base AUN yang akan di implementasikan pada Gambar 5.

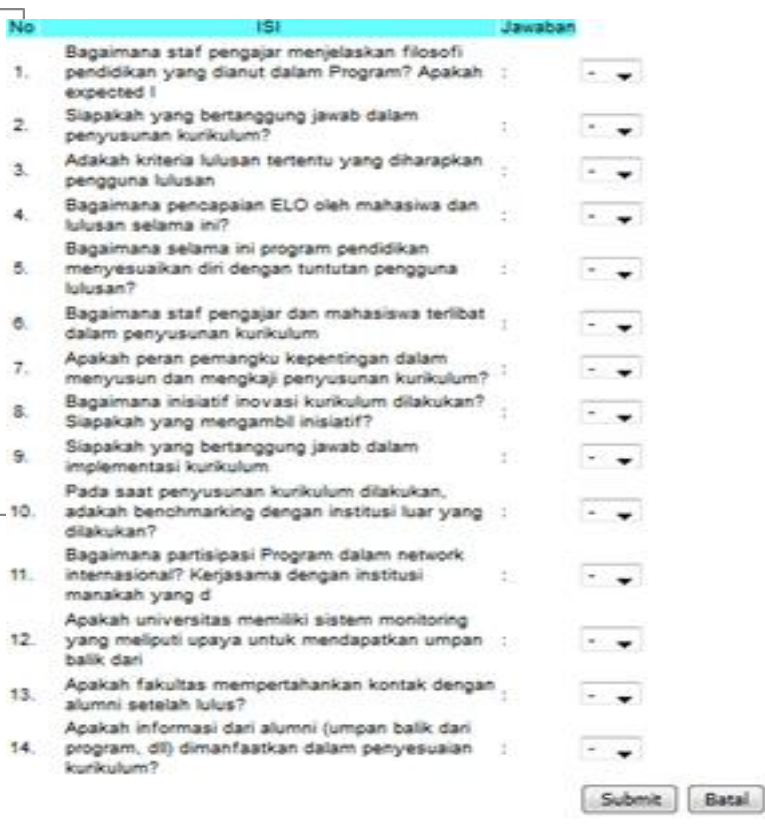

Gambar 5. Input servqual rule base AUN 
Proses ini merupakan proses dari servqual rule base AUN yang nilai paling rendah akan di evaluasi sesuai variable servqual, yang ditunjukan pada Gambar 6.

Teknik Mesin

Nilai $\Rightarrow$ A001 Nilai terendah $\Rightarrow 2$

maka yang harus dievaluasi Adalah $\Rightarrow$ Reliability Nilai terendah $\Rightarrow 2$

Range diperbaiki $\Rightarrow$ D.0004yang harus dievaluasi adalah kriteria Academic staff quality

Range diperbaiki $\Rightarrow D .0004 y a n g$ harus dievaluasi adalah kriteria Programme Structure

Range diperbaiki $\Rightarrow D .0004 y a n g$ harus dievaluasi adalah kriteria Teaching \& Learning Strategy

Range diperbaiki $\Rightarrow D .0004 y a n g$ harus dievaluasi adalah kriteria Stakeholders satisfaction

\begin{tabular}{|l|c|c|c|c|c|}
\hline & No & & Assurance Empathy & Responsiveness & Reliabilty Fasilitas \\
\hline \multicolumn{1}{|l|}{1.} & 4 & 4 & 4 & 2 & 4 \\
\hline Submit & & Batal & & & \\
\hline
\end{tabular}

NILAI AUN $=3.6$

Hasil Grade Adequate as

Expected

\section{Gambar 6. Evaluasi servqual rule base AUN}

Output dari sistem servqual rule base AUN berupa grafik batang yang ditunjukan nilai capaian masing-masing program studi yang telah dinilai, yang akan ditunjukan pada Gambar 7.

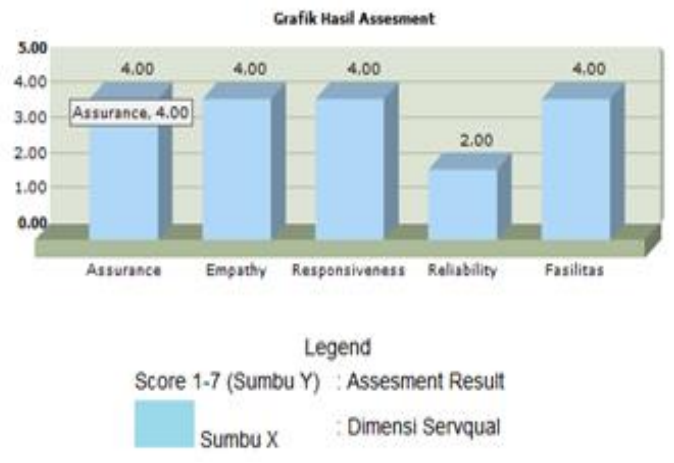

Gambar 7. Dasbord servqual rule base AUN

\section{Kesimpulan}

Pada penelitian kualitas program studi dengan menerapkan servqual rule base Asean University Network dapat ditarik beberapa kesimpulan bahwa hasil dari assesment Asean University Network memiliki perbedaan dengan hasil penilaian metode servqual rule base Asean University Network, karena saat penilaian di AUN yang di rata-rata masingmasing kriteria, sedangkan pada servqual rata-rata didapat pada masing-masing dimensi. Korelasi regresi linier 0,985 dan perhitungan diterima karena tingkat validitas mencapai $97 \%$.

\section{Ucapan Terima Kasih}

Terima kasih diucapkan Bapak Budi Setia Sasongko yang telah memberikan data dalam penelitian ini selaku sekretaris LP2MP UNDIP yang telah meluangkan waktunya untuk membimbing tesis ini.

\section{Daftar Pustaka}

Albari, A. A. F., Yarmohammadian, M. H., Esteki, M., 2011. Assessment of quality of education a non-governmental university via servqual model. Procedia - Social and Behavioral Sciences, 15, 2299-2304.

Aoudia, M., Marji, K., dan Alqahsi, D., 2015. Assessment Of Higher Education Quality By Using Cohort Of First- Year In University. Procedia - Social and Behavioral Sciences, 191, 330-335.

Carrasco, R. A., Munoz-Leiva, F., SanchezFernandez, J., dan Liebana-Cabanillas, F. J., 2012. A model for the integration of e-financial services questionnaires with servqual scales under fuzzy linguistic modeling. Expert Systems with Applications, 39(14), 11535-11547.

Chou, C., Liu, L., Huang, S., Yih, J., dan Han, T., 2011. An evaluation of airline service quality using the fuzzy weighted SERVQUAL method. Applied Soft Computing Journal, 11(2), 21172128.

Gajaseni, N., Asean University Network, 2011. Guide to AUN Actual Quality Assessment at Programme Level Version No. Thailand: AUN Secretariat.

Jiwantara, K., Sutrisno, A., Neyland, J. S. C., 2012. Penyuluhan Bahasa Indonesia Praktis di Balai Bahasa Provinsi Sulawesi Utara.

Kang, H., Bradley, G., 2002. Measuring the performance of IT services. International Journal of Accounting Information Systems, 3(3), 151164.

Kendall, K. E., Kendall, J. E., 2011. Systems Analysis and Design (8th ed). Prentice Hall, One Lake Street, Upper Saddle River, New Jersey 07458.

Khan, Iqbal, M., Shehab, M.M., and Waleed, M. Z., 2014. Developing and qualifying civil engineering programs for ABET accreditation. Journal of King Saud University - Engineering Sciences. 2014.09.001.

Lupo, T., 2013, A fuzzy servqual based method for reliable measurements of education quality in italian higher education area. Expert Systems with Applications, 40(17), 7096-7110.

Marimin, 2004. Teknik dan Aplikasi Pengambilan Keputusan Kriteria Majemuk. Jakarta: Grasindo.

Myhre, O., Fjellheim, K., Ringnes, H., Reistad, T., Longva, K. S., Ramos, T. B., 2013. Development of environmental performance indicators supported by an environmental information system: Application to the Norwegian defence sector. Ecological Indicators, 29, 293-306. 
Permadi, B., 1992. Analytical Hierarchy Proses. Universitas Indonesia: Universitas-Studi, Pusat Antar Ekonomi.

Purnamawati, E., 2009. Analisis Kualitas Layanan dengan Metode Servqual dan AHP di Dinas Kependudukan dan Pencatatan Sipil di Surabaya.

Saaty, T. L., 1993. Pengambilan Keputusan Bagi Para Pemimpin, Proses Hirarki Analitik Untuk Pengambilan Keputusan Dalam Situasi Yang Kompleks. Jakarta: Pustaka Binama Pressido.

Sudjana, 2005. Metoda Statistika edisi 6, Bandung: PT Tarsinto.
Suryadi, K. dan Rahmandani, M., A., 1998. Sistem Pendukung Keputusan. Bandung: PT Remaja Rosdakarya.

Udo, G. J., Bagchi, K. K., Kirs, P. J., 2011. Using servqual to assess the quality of e-learning experience. Computers in Human Behavior, 27(3), 1272-1283.

Yousapronpaiboon, K., 2014. 5 th World Conference on Educational Sciences - wces servqual: Measuring higher education service quality in Thailand. Procedia - Social and Behavioral Sciences, 116, 1088-1095 